Cereal Research Communications 39(4), pp. 560-568 (2011)

DOI: $10.1556 / C R C .39 .2011 .4 .11$

\title{
Species Pattern and Phylogenetic Relationships of Trichoderma Strains in Rice Fields of Southern Caspian Sea, Iran
}

\author{
S. NAEIMI ${ }^{1}$, S.A. KHODAPARAST ${ }^{2}$, M. JAVAN-NIKKHAH ${ }^{3}$, C. VÁGVÖLGYI ${ }^{4}$ and L. KREDICS ${ }^{4 *}$ \\ ${ }^{1}$ Iranian Research Institute of Plant Protection, Tehran, P.O. Box 19395-1454, Iran \\ ${ }^{2}$ Department of Plant Protection, Faculty of Agriculture, University of Guilan, \\ Rasht 41635-1314, P.O. Box 41889, Iran \\ ${ }^{3}$ Department of Plant Protection, Faculty of Agriculture, University of Tehran, Karaj 3158711167, Iran \\ ${ }^{4}$ Department of Microbiology, University of Szeged, Közép fasor 52, H-6726 Szeged, Hungary
}

(Received 15 December 2010; accepted 3 March 2011)

\begin{abstract}
As a first step of a project aimed at the identification of potential biocontrol agents of Rhizoctonia solani, the rice sheath blight fungus, we surveyed the biodiversity of the genus Trichoderma based on sequence of the internal transcribed spacer (ITS) 1 and 2 of the ribosomal RNA gene cluster in paddy fields in Mazandaran province, Northern Iran. Amongst the six obtained species of Trichoderma, T. harzianum and T. virens proved to be the most frequent species in this habitat. Sequence alignment and phylogenetic analysis revealed that the T. harzianum isolates can be divided into 14 different ITS genotypes clustering in four groups. Our results are in agreement with previous molecular studies, which also revealed that T. harzianum is a complex species comprising more or less different ITS genotypes. T. virens was not as diverse as $T$. harzianum and three different genotypes were distinguished which constituted only one cluster. All $T$. atroviride and T. hamatum strains had identical ITS sequences.
\end{abstract}

Keywords: Trichoderma, T. harzianum, rice, paddy fields, biodiversity, ITS, phylogeny

\section{Introduction}

Sheath blight caused by Rhizoctonia solani is one of the most serious rice diseases worldwide. The disease is currently managed only through excessive application of chemical fungicides which are toxic and non-environmentally friendly. Therefore, greater emphasis is now given on biological control as safe and effective alternate strategy.

Species of the genus Trichoderma (teleomorph: Hypocrea) are ubiquitous and frequently dominant components of the soil microflora in widely varying habitats (Klein and Eveleigh 1998). Some of them are economically important because of their production of enzymes and antibiotics and their action as biocontrol agents against a variety of plant pathogens (Hjeljord and Tronsmo 1998). Trichoderma species are also considered to be opportunistic, avirulent plant symbionts, promoters of plant growth (Harman et al. 2004)

* Corresponding author; E-mail: kredics@bio.u-szeged.hu 
and inducers of resistance in crops (Howell 2003). In contrast to their usefulness, however, some species cause the so-called "green mould disease" in mushroom cultivation (Hatvani et al. 2007), while others emerge as opportunistic pathogens of humans (Kredics et al. 2003).

The development of species concepts in the case of the genus Trichoderma has been extensively reviewed (Druzhinina and Kubicek 2005; Druzhinina et al. 2006). Initially, the concept of "aggregate" species was adopted, and nine aggregates were distinguished (Rifai 1969) which were not biological species. Later, the revision of the genus resulted in the establishment of five sections (Bissett 1984, 1991a-c). Due to the homoplasy of morphological characters, morphological identification of the Trichoderma isolates at the species level has proved difficult and unreliable (Kullnig-Gradinger et al. 2002). Therefore, comprehensive studies have resorted to molecular methods for species identification. Various molecular approaches, including sequence analysis of the internal transcribed spacer (ITS) region within the ribosomal RNA gene cluster, ITS ribotyping, restriction fragment length polymorphism (RFLP) analysis, randomly amplified polymorphic DNA (RAPD) or universally primed PCR (UP-PCR) fingerprinting have been established to clarify the taxonomy of the genus (Lieckfeldt et al. 1998). Sequence analysis of ITS1 and 2 has been especially reliable for characterization of Trichoderma isolates to the species level (Kindermann et al. 1998; Ospina-Giraldo et al. 1999; Hermosa et al. 2000). Druzhinina et al. (2005) developed a DNA barcode system for species identification of Trichoderma and Hypocrea based on a library of species-specific oligonucleotide sequences from the ITS1 and 2 loci. Ribosomal DNA sequences have also been used to phylogenetically evaluate the sections of Trichoderma proposed by Bissett (Kuhls et al. 1997; Kindermann et al. 1998; Dodd et al. 2000; Lieckfeldt and Seifert 2000).

Natural ecosystems were investigated in details by molecular methods for Trichoderma biodiversity including a mid-European, primeval floodplain-forest (Wuczkowski et al. 2003), soils from Russia, Nepal, Northern India (Kullnig et al. 2000), South-East Asia (Kubicek et al. 2003), Sardinia (Migheli et al. 2009) and South America (Hoyos-Carvajal et al. 2009). A series of new genotypes as well as new phylogenetic species of Trichoderma have been recognized during these studies. Furthermore, the investigation of agricultural soils may also reveal interesting data about Trichoderma biodiversity (Gherbawy et al. 2004; Mulaw et al. 2010), especially from the point of view of biocontrol applications, as the rhizosphere of agricultural soils is an ideal source of potential biocontrol agents. The purpose of the present work was to study the biodiversity of the genus Trichoderma in paddy rice fields based on the sequence analysis of the ITS region, with special emphasis on strains of biocontrol relevance.

\section{Material and Methods}

\section{Fungal isolates}

The strains of Trichoderma spp. examined in this study are listed in Table 1. All strains were isolated by the authors from paddy rice fields located at the southern coast of the Cas- 
pian Sea, Iran (Naeimi et al. 2010). The strains are representing six species and were isolated from geographically widely distributed samples throughout the Mazandaran province, the largest rice growing area in the country. All strains that proved to possess biocontrol potential against $R$. solani, the rice sheath blight pathogen in a previous study

Table 1. Trichoderma strains used during this study

\begin{tabular}{|c|c|c|}
\hline Species & Isolate code ${ }^{a}$ & $\begin{array}{l}\text { GenBank } \\
\text { accession } \\
\text { number }\end{array}$ \\
\hline T. asperellum & $\mathrm{BS} 3-8^{\mathrm{b}}$ & EU821799 \\
\hline T. atroviride & $\begin{array}{l}\text { AS8, AS18-5, CS2-1, CS5-1, DS111, DS112, DS121, DS122, DS501, } \\
\text { DS602, DS606 }\end{array}$ & EU821797 \\
\hline T. brevicompactum & DS701 & EU821800 \\
\hline T. hamatum & SS11-2, SS108-2, DS302 & EU821798 \\
\hline \multirow[t]{14}{*}{ T. harzianum } & $\begin{array}{l}\text { AD1-1, AS3-3, AS3-5 } \text {, AS4-1, AS4-2, AS4-3, AS5, AS15-3, AS19-1, } \\
\text { AS19-2, AS19-3, AS19-4, AS20-1, AS20-2, AS20-3, AS20-4, AS20-5, } \\
\text { AS21-1, AS21-2, AS21-3, AS22-1, AS22-2, AS22-3, AS22-4, BS7-1, } \\
\text { BS7-2, BS7-3, SS1-1, SS1-2, SS10-4, SS10-5, DS201, DS202, DS203, } \\
\text { DS204, DS205, DS322, BP4, BL1-2, BL1-3, BL1-4, BL2-1, BL2-5, } \\
\text { BL3-2, BL3-3, BL3-5, BL3-9, BL4-1, BL6-3, BL7-3, BL7-5, BL8-2, } \\
\text { BL9-2, BL9-3, BL9-5, BL9-6, BLP2, BLP7, BLP8 }\end{array}$ & EU821780 \\
\hline & AS2-1, AS2-2, AS2-3, AS17-2, BLP5, BS1-1, BS1-3, BS1-4, SS10-2 & EU821781 \\
\hline & AD7, AS15-1, AS15-4, AS15-6, AS15-7, AS16-1, AS17-3, AS17-6 & EU821782 \\
\hline & CS1-1, CS4-2, DS603, DS604, DS801, DS803 & EU821783 \\
\hline & $\mathrm{AD} 1-2, \mathrm{AD} 6$ & EU821784 \\
\hline & DS301 & EU821785 \\
\hline & SS6-1 & EU821786 \\
\hline & SS7-1 & EU821787 \\
\hline & SS10-3 & EU821788 \\
\hline & AS12-1, AS12-2, AS12-3, AS12-4 & EU821789 \\
\hline & SS8-4 & EU821790 \\
\hline & $\begin{array}{l}\text { AS16-3, AS16-4, AS16-5, BL2-2, BL2-3, BL3-7, BL3-8, BL7-4, } \\
\text { BL7-6, BL8-5, BLP1, CS4-3, DS403, DS404, DS502, DS507, DS555 }\end{array}$ & EU821791 \\
\hline & SS6-2, SS6-21, SS103 & EU821792 \\
\hline & DS303, DS304 & EU821793 \\
\hline \multirow[t]{3}{*}{ T. virens } & $\begin{array}{l}\text { AD1-3, AD1-5, AS1-1, AS1-2, AS3-1, AS3-2, AS3-4, AS6-1, AS6-2, } \\
\text { AS6-3, AS6-4, AS10-1, AS10-2, AS10-3, AS10-4, AS10-5, AS10-6, } \\
\text { AS10-7, AS11-1, AS11-2, AS11-3, AS11-4, AS14-1, AS14-2, AS14-3, } \\
\text { BL1-5, BL3-1, BL8-1, BS1-2, BS2-1, BS2-2, BS2-3, BS2-4, BS2-5, } \\
\text { BS2-6, BS2-7, CS1-2, CS1-3, SS109, DS402, DS404, DS405, DS421, } \\
\text { DS601 }\end{array}$ & EU821794 \\
\hline & $\begin{array}{l}\text { AS15-2, AS15-5, AS16-2, AS16-22, AS18-1, AS18-2, AS18-3, } \\
\text { AS18-4, BS3-1, BS3-2, BS3-3, BS3-4, BS3-5, BS3-6, BS3-11, SS7-3, } \\
\text { DS100, DS508, DS509, DS901, DS905 }\end{array}$ & EU821795 \\
\hline & AS17-1, AS17-4, AS17-5, SS8-1 & EU821796 \\
\hline
\end{tabular}

\footnotetext{
${ }^{\mathrm{a}}$ All isolates obtained from rice fields in Mazandaran province, Iran; ${ }^{\mathrm{b}}$ Isolates were grouped according to their ITS genotypes; ${ }^{\mathrm{c}}$ Identical GenBank accession numbers indicate that the sequences of the corresponding isolates are identical; ${ }^{\mathrm{d}}$ Promising biocontrol strains are set in bold.
} 
(Naeimi et al. 2010) were included in this analysis. Single spore isolates were maintained on potato dextrose agar (PDA; Merck, Germany) slants at $4^{\circ} \mathrm{C}$.

\section{ITS (PCR) amplification}

For DNA isolation, the mycelium plug of each strain was placed on cellophane disk sterilized by autoclaving in water and placed on the surface of a yeast dextrose agar medium ( 5 $\mathrm{g}$ of yeast extract, $5 \mathrm{~g}$ of dextrose and $20 \mathrm{~g}$ of agar per liter). Fungal cultures were kept for 2-3 days at room temperature. The fresh mycelium was scraped off and ground with a mortar and a pestle in liquid nitrogen. Total DNA was extracted using the GenElute Plant Genomic DNA Miniprep Kit (Sigma, USA) following the manufacturer's instructions.

A nuclear rDNA region, containing the internal transcribed spacers 1 and 2 (ITS1 and 2 ) and the 5.8S rRNA gene was amplified using the primers ITS1 and ITS4 (White et al. 1990). PCR amplifications were performed as described previously (Hermosa et al. 2000). Amplicons were purified with the GenElute PCR Clean-up Kit (Sigma, USA) and sequenced at Macrogen Inc., South Korea. ITS sequences were submitted to the NCBI GenBank Database, accession numbers are listed in Table 1. In order to identify the isolates at the species level, ITS sequence analysis was carried out with the aid of the program TrichOkey 2.0 (Druzhinina et al. 2005) available online at http://www.isth.info/.

\section{Phylogenetic analysis}

Additional Trichoderma sequences retrieved from the GenBank were included in this study for comparison. The obtained sequences were aligned using the Clustal X 2.0 package. Phylogenetic trees were obtained from the data by the distance and maximum-parsimony (MP) methods using PAUP* 4.0b10. In the distance method, a neighbour-joining (NJ) tree was obtained using Kimuras's 2-parameter distances. For the parsimony analysis we used the maximum parsimony (MP) method with a heuristic search, starting tree(s) obtained via stepwise addition. All sites were treated as unordered and unweighted, with gaps treated as missing data. The branch-swapping algorithm was TBR, the MULPARS option was in effect, and branches were collapsed if maximum branch length was zero. The strength of the internal branches from the resulting trees were tested by bootstrap analysis using 1000 replications in both distance and parsimony analyses. T. aureoviride (teleomorph: Hypocrea aureoviridis) was used as the outgroup taxon.

\section{Results}

A total number of 201 Trichoderma strains were isolated from samples deriving from Northern Iranian rice fields at 45 different geographic locations. Based on the TrichOkey 2.0 diagnosis, more than $50 \%$ of the isolates proved to belong to the species $T$. harzianum (section Pachybasium B, clade Lixii/catoptron). The second most frequent species occurring in the rice field samples was T. virens (section Pachybasium B, clade Virens) with 69 isolates $(34 \%)$. Besides T. harzianum and T. virens, strains belonging to four other Trichoderma species could be isolated from the examined rice field samples: 11 strains of T. atroviride (section Trichoderma, clade Rufa), three strains of T. hamatum and one 
strain of T. asperellum (section Trichoderma, clade Pachybasium A), and one strain of T. brevicompactum (section Pachybasium B, "Lone lineages"). No known section Longibrachiatum species were found, suggesting that members of this section are of low abundance or absent from the rice field habitat examined. The results revealed that T. harzianum was the dominant Trichoderma species in both the rhizosphere and the phyllosphere of Northern Iranian rice field habitats, while $T$. virens was more abundant in the rhizosphere than in the phyllosphere. Interestingly, among six obtained species, only $T$. harzianum and T. virens were isolated from the phyllosphere. Altogether, 14 and 3 different ITS genotypes were detected for T. harzianum (Fig. 1A) and T. virens, respectively. In the case of T. atroviride and T. hamatum, no intraspecific variation of ITS sequences could be observed.

A phylogenetic analysis was performed based on the ITS sequences of the isolates, the sequences used for the analysis were 497 to $518 \mathrm{bp}$ after manual contig trimming. The alignment data matrix consisted of 42 taxa and 562 characters, of which 465 characters were constant, 97 characters were variable and 61 variable characters were phylogenetically informative for parsimony analysis. The NJ analysis using Kimura's 2-parameter distance yielded a tree topology, which is shown in Fig. 1B. Best tree with 144 steps $(\mathrm{CI}=$ $0.8542, \mathrm{RI}=0.9095, \mathrm{RC}=0.7768, \mathrm{HI}=0.1458$ ) was constructed by the MP analysis (tree not shown). Major clades were supported by both methods. The 14 genotypes of T. harzianum could be divided into four groups based on the phylogenetic analysis (Fig. 1B). Three and two isolates proved to belong to the previously described genotypes 1 known from Krasnoyarsk, Siberia and 2a known from Western Ural, respectively (Kullnig et al. 2000). Fifty-nine T. harzianum isolates (including two biocontrol strains, AS3-5 and AS20-3) have the same genotype, while five genotypes were represented by single isolates only (DS301, SS6-1, SS7-1, SS10-3 and SS8-4). Most of the T. virens isolates proved to be related with the $T$. virens ex-type strain DAOM 167651, while two isolates represented an ITS genotype that is also known for $T$. virens isolates from winter wheat rhizosphere in South Hungary (Szekeres et al. unpublished). The T. atroviride isolates proved to be related with the ex-type strain CBS 142.95. The ITS sequence of the three $T$. hamatum isolates represented an ITS-type differing from the ex-type strain DAOM 167057 in a G to A substitution at position 364. The ITS sequence of the single T. asperellum isolate differed from that of the type strain CBS 433.97 in a single $\mathrm{T}$ deletion at position 152 .

\section{Discussion}

Based on the results of this study, T. harzianum is the most abundant and genetically most diverse member of the genus in paddy fields in the Southern coasts of Caspian Sea, Iran. This finding supports the results of other researchers who reported that T. harzianum is the dominant species in rice fields in several Asian countries (Nagamani and Mew 1987; Mostafa Kamal and Shahjahan 1995; Cumagun et al. 2000; Kullnig et al. 2000; Kubicek et al. 2003). T. harzianum was frequently reported as a diverse and complex species. It was one of nine "aggregate species" described by Rifai (1969) and defined as comprising 
A

\begin{tabular}{|c|c|}
\hline Strain & Characteristic sequence area \\
\hline Position & $162 \downarrow($ ITS1) $402 \downarrow$ (ITS2) \\
\hline AS16-3 & 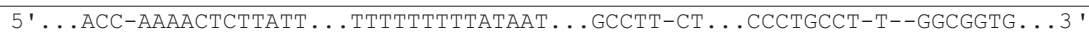 \\
\hline AS16-1 & . ACC-AAAACTCTTATT . . TTTTTTTT-AATAAT . . GCCTT-CT . . CCCTGCCT-T--GGCGGTG . .3' \\
\hline AS2-1 & $55^{\prime} \ldots$ ACC-AAAACTCTTATT $\ldots$.TTTTTTT--ATAAT $\ldots$ GCCTT-CT . . CCCTCCCT-TAGCGGGGTG $\ldots .3$ \\
\hline AS20-3 & 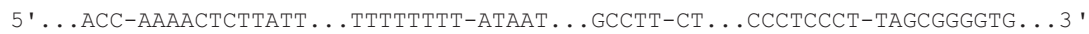 \\
\hline $\operatorname{cs} 1-1$ & 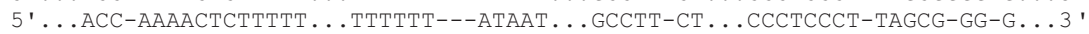 \\
\hline SS10-3 & 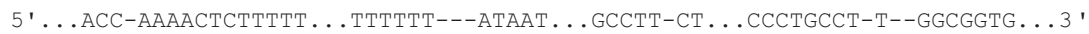 \\
\hline AS12-2 & 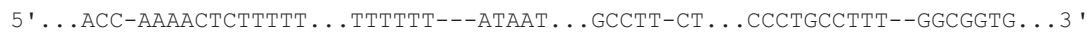 \\
\hline SS7-1 & . АCC-AAAACTCTTTTT . . .TTTTTT--ATAAAT . . GCCTT-CT . . СCCTGCCTCT--GGCGGTG . . .3' \\
\hline $\mathrm{AD} 1-2$ & 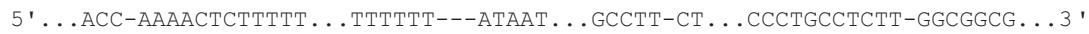 \\
\hline SS8-4 & 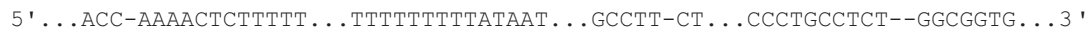 \\
\hline ss6-1 & 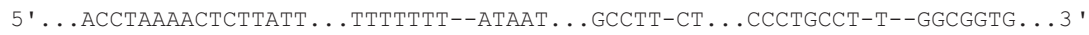 \\
\hline DS303 & 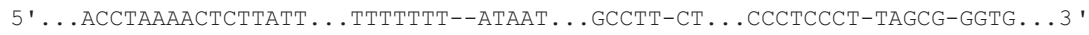 \\
\hline ss6-2 & 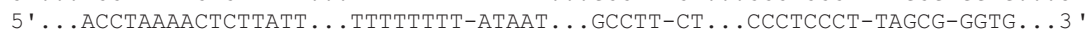 \\
\hline DS301 & 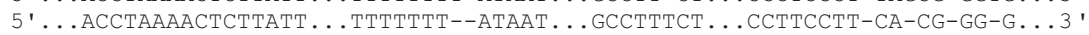 \\
\hline
\end{tabular}

B

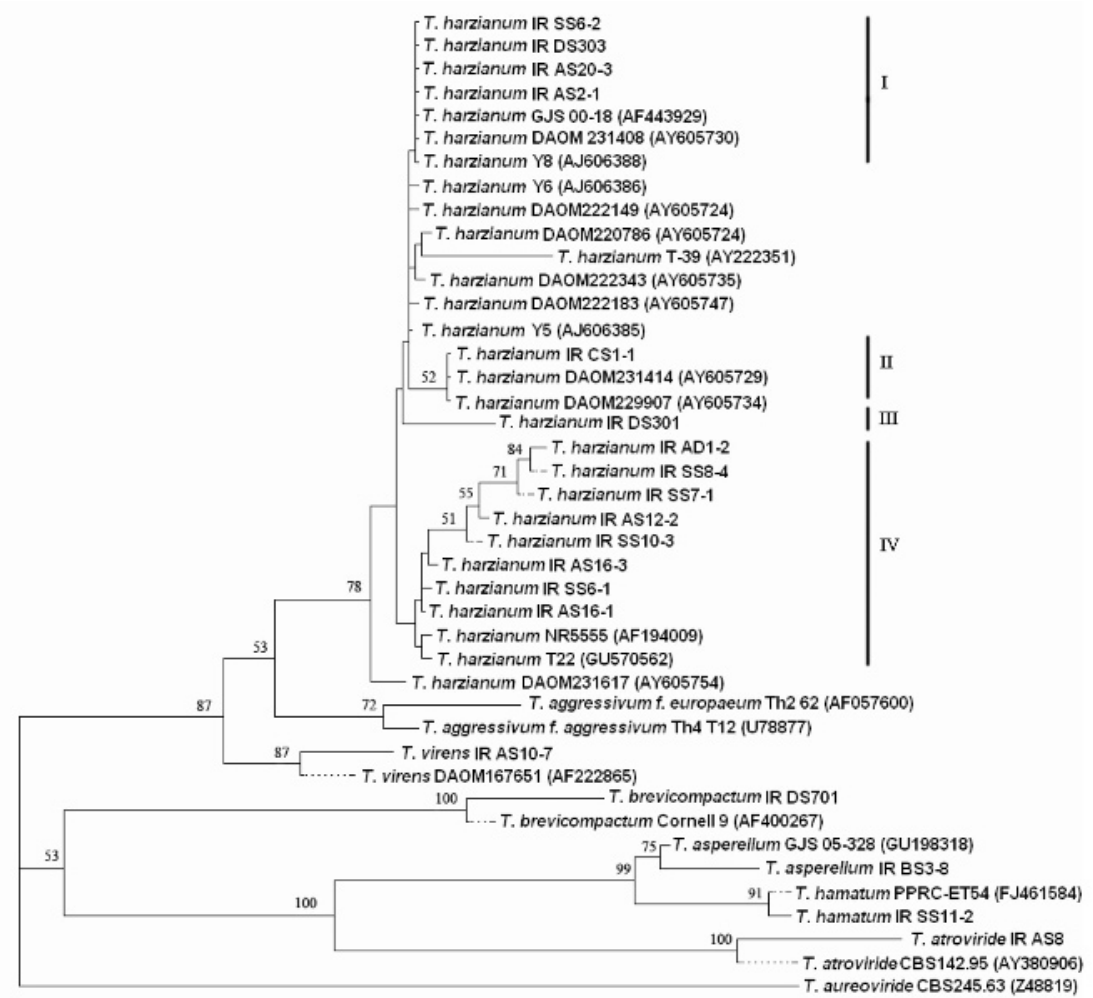

Figure 1. Biodiversity of Trichoderma strains isolated from rice fields based on ITS sequences. A) Alignment of characteristic sequence areas within ITS1 and ITS2 of T. harzianum isolates. Arrows indicate positions within the ITS region in relation to the first nucleotide of ITS1. B) Phylogenetic tree based on ITS-sequences. Accession numbers of reference sequences from the GenBank are shown in parentheses. Numbers above branches are bootstrap values from 1000 replications. Iranian isolates are marked as IR.

The four clades containing Iranian T. harzianum isolates are indicated 
more than one morphologically cryptic species. Gomez et al. (1997) suggested that $T$. harzianum is the collective name of a set of asexual fungal strains which exhibit heterogeneity in genome structure, DNA sequence and behavior. Kullnig-Gradinger et al. (2002) stated that in contrast to the identity or high similarity of ITS1 and 2 sequences in most taxa, T. harzianum exhibited a considerably higher variation in the ITS1 and also ITS2 sequences. Chaverri et al. (2003) studied a wide morphological and geographic diversity of Trichoderma isolates using four genes and concluded that $T$. harzianum is a species complex with distinct, partly geographically defined phylogenetic lineages that lacked diagnostic morphological characters. It is possible that variants of $T$. harzianum arose from recombinants during sexual reproduction (Chaverri et al. 2003; Sharma et al. 2009). In a recent work, Druzhinina et al. (2010) analysed DNA sequence data from three unlinked loci in the case of 93 T. harzianum strains, and suggested a complex speciation history within the T. harzianum species complex which is based on coexistence and interaction of organisms with different evolutionary histories and on the absence of strict genetic borders between them.

There was no correlation of the ITS genotypes with either the geographic locations or with the isolation source (rhizosphere vs. rice phyllosphere). Rather, two or more genotypes were isolated from the same habitats, demonstrating that the different genotypes coexist with each other. In addition, since seven biocontrol strains from our previous study have five different genotypes, we could not find any relation between the ITS genotype and the antagonistic activities of Trichoderma strains.

In conclusion, the community of Trichoderma in rice fields of Northern Iran is dominated by beneficial taxa widely used as biocontrol agents against plant pathogenic fungi (T. harzianum, T. virens and T. atroviride), indicating that the rice rhizosphere and phyllosphere may be a rich source of potential biocontrol isolates.

\section{Acknowledgements}

This work was aided by the project named "TÁMOP-4.2.1/B-09/1/KONV-2010-0005 Creating the Center of Excellence at the University of Szeged", which is supported by the European Union and co-financed by the European Regional Fund.

\section{References}

Bissett, J. 1984. A revision of the genus Trichoderma. I. Sect. Longibrachiatum sect. nov. Can. J. Bot. 62:924-931.

Bissett, J. 1991a. A revision of the genus Trichoderma. II. Infrageneric classification. Can. J. Bot. 69:2357-2372.

Bissett, J. 1991b. A revision of the genus Trichoderma. III. Sect. Pachybasium. Can. J. Bot. 69:2373-2417.

Bissett, J. 1991c. A revision of the genus Trichoderma. IV. Additional notes on section Longibrachiatum. Can. J. Bot. 69:2418-2420.

Chaverri, P., Castlebury, L.A., Samuels, G.J., Geiser, D.M. 2003. Multilocus phylogenetic structure within the Trichoderma harzianum/Hypocrea lixii complex. Mol. Phylogenet. Evol. 23:302-313. 
Cumagun, C.J.R., Hockenhull, J., Lübeck, M. 2000. Characterization of Trichoderma isolates from Philippine rice fields by UP-PCR and rDNA-ITS1 analysis: Identification of UP-PCR markers. J. Phytopathol. 148:109-115.

Dodd, S.L., Crowhurst, R.N., Rodrigo, A.C., Samuels, G.J., Hill, R.A., Stewart, A. 2000. Examination of Trichoderma phylogenies derived from ribosomal DNA sequence data. Mycol. Res. 104:23-34.

Druzhinina, I., Kopchinskiy, A., Komoñ, M., Bissett, J., Szakacs, G., Kubicek, C.P. 2005. An oligonucleotide barcode for species identification in Trichoderma and Hypocrea. Fungal Genet. Biol. 42:813-828.

Druzhinina, I., Kubicek, C.P. 2005. Species concepts and biodiversity in Trichoderma and Hypocrea: from aggregate species to species clusters? J. Zhejiang Univ. Sci. 6:100-112.

Druzhinina, I.S., Kopchinskiy, A.G., Kubicek C.P. 2006. The first 100 Trichoderma species characterized by molecular data. Mycoscience 47:55-64.

Druzhinina, I.S., Kubicek, C.P., Komoñ-Zelazowska, M., Mulaw, T.B., Bissett, J. 2010. The Trichoderma harzianum demon: Complex speciation history resulting in coexistence of hypothetical biological species, recent agamospecies and numerous relict lineages. BMC Evol. Biol. 10:94.

Gherbawy, Y., Druzhinina, I., Shaban, G.M., Wuczkowsky, M., Yaser, M., El-Naghy, M.A., Prillinger, H.J., Kubicek, C.P. 2004. Trichoderma populations from alkaline agricultural soil in the Nile valley, Egypt, consist of only two species. Mycol. Prog. 3:211-218.

Gomez, I., Chet, I., Herrera-Estrella, A. 1997. Genetic diversity and vegetative compatibility among Trichoderma harzianum isolates. Mol. Gen. Genet. 256:127-135.

Harman, G.E., Howell, C.R., Viterbo, A., Chet, I., Lorito, M. 2004. Trichoderma species - opportunistic avirulent plant symbionts. Nature Rev. Microbiol. 2:43-56.

Hatvani, L., Antal, Z., Manczinger, L., Szekeres, A., Druzhinina, I.S., Kubicek, C.P., Nagy, A., Nagy, E.,Vágvölgyi, C., Kredics, L. 2007. Green mould diseases of Agaricus and Pleurotus are caused by related but phylogenetically different Trichoderma species. Phytopathology 97:532-537.

Hermosa, M.R., Grondona, I., Iturriaga, E.A., Diaz-Minguez, J.M., Castro, C., Monte, E., Garcia-Acha, I. 2000. Molecular characterization of biocontrol isolates of Trichoderma. Appl. Environ. Microbiol. 66:1890-1898.

Hjeljord, L., Tronsmo, A. 1998. Trichoderma and Gliocladium in biological control: An overview. In: Harman, G.E., Kubicek, C.P. (eds), Trichoderma and Gliocladium. Enzymes, Biological Control and Commercial Applications, vol. II. Taylor \& Francis, London, UK, pp. 131-151.

Howell, C.R. 2003. Mechanisms employed by Trichoderma species in the biological control of plant diseases: The history and evolution of current concepts. Plant Dis. 87:4-10.

Hoyos-Carvajal, L., Orduz, S., Bissett, J. 2009. Genetic and metabolic biodiversity of Trichoderma from Colombia and adjacent neotropic regions. Fungal Genet. Biol. 46:615-631.

Kindermann, J., El-Ayouti, Y., Samuels, G.J., Kubicek, C.P. 1998. Phylogeny of the genus Trichoderma based on sequence analysis of the internal transcribed spacer region 1 of the rDNA clade. Fungal Genet. Biol. 24:298-309.

Klein, D., Eveleigh, E., 1998. Ecology of Trichoderma. In: Kubicek, C.P., Harman, G.E. (eds), Trichoderma and Gliocladium. Basic Biology, Taxonomy and Genetics. Taylor \& Francis Ltd., London, UK, pp. 57-74.

Kredics, L., Antal, Z., Dóczi, I., Manczinger, L., Kevei, F., Nagy, E. 2003. Clinical importance of the genus Trichoderma. A review. Acta Microbiol. Immunol. Hung. 50:105-117.

Kubicek, C.P., Bissett, J., Druzhinina, I., Kullnig-Gradinger, C.M., Szakacs, G. 2003. Genetic and metabolic diversity of Trichoderma: A case study on South East Asian isolates. Fungal Genet. Biol. 38:310-319.

Kuhls, K., Lieckfeldt, E., Samuels, G.J., Meyer, W., Kubicek, C.P., Börner, T. 1997. Revision of Trichoderma section Longibrachiatum including related teleomorphs based on an analysis of ribosomal DNA internal transcribed spacer sequences. Mycologia 89:442-460.

Kullnig, C., Szakacs, G., Kubicek, C.P. 2000. Molecular identification of Trichoderma species from Russia, Siberia and the Himalaya. Mycol. Res. 104:1117-1125.

Kullnig-Gradinger, C., Szakacs, G., Kubicek, C.P. 2002. Phylogeny and evolution of the genus Trichoderma: A multigene approach. Mycol. Res. 106:757-767.

Lieckfeld, E., Seifert, K.A. 2000. An evaluation of the use of ITS sequences in the taxonomy of the Hypocreales. Stud. Mycol. 45:35-44.

Lieckfeldt, E., Kuhls, K., Muthumeenakshi, M. 1998. Molecular taxonomy of Trichoderma and Gliocladium and their teleomorphs. In: Kubicek, C.P., Harman, G.E. (eds), Trichoderma and Gliocladium, Vol. 1: Basic Biology, Taxonomy and Genetics. Taylor \& Francis, London, UK, pp. 35-74.

Cereal Research Communications 39, 2011 
Migheli, Q., Balmas, V., Komoñ-Zelazowska, M., Scherm, B., Fiori, S., Kopchinskiy, A.G., Kubicek, C.P., Druzhinina, I.S. 2009. Soils of a Mediterranean hot spot of biodiversity and endemism (Sardinia, Tyrrhenian Islands) are inhabited by pan-European, invasive species of Hypocrea/Trichoderma. Environ. Microbiol. 11:35-46.

Mostafa Kamal, M.D., Shahjahan, A.K.M. 1995. Trichoderma in rice field soils and their effect on Rhizoctonia solani. Bangladesh J. Bot. 24:75-79.

Mulaw, T.G., Kubicek, C.P., Druzhinina, I.S. 2010. The rhizosphere of Coffea arabica in its native highland forests of Ethiopia provides a niche for a distinguished diversity of Trichoderma. Diversity 2:527-549.

Naeimi, S., Okhovvat, S.M., Javan-Nikkhah, M., Kredics, L., Khosravi, V. 2010. Biological control of Rhizoctonia solani AG1-1A, the causal agent of rice sheath blight with Trichoderma strains. Phytopathol. Mediterr. 49: 287-300.

Nagamani, A., Mew, T.W. 1987. Trichoderma in Philippine rice field soils. Int. Rice Res. Newslett. 12:25.

Ospina-Giraldo, M.D., Royse, D.J., Chen, X., Romaine, C.P. 1999. Molecular phylogenetic analyses of biological control strains of Trichoderma harzianum and other biotypes of Trichoderma spp. associated with mushroom green mold. Phytopathology 89:308-313.

Rifai, M.A. 1969. A revision of the genus Trichoderma. Mycol. Pap. 116:1-116.

Sharma, K., Mishra, A.K., Misra, R.S. 2009. Morphological, biochemical and molecular characterization of Trichoderma harzianum isolates for their efficacy as biocontrol agents. J. Phytopathol. 157:51-56.

White, T.J., Bruns, T., Lee, S., Taylor, J. 1990. Amplification and direct sequencing of fungal ribosomal RNA genes for phylogenetics. In: Innes, M.H., Gelfand, D.H., Sninsky, J.J., White, T.J. (eds), PCR protocols. Academic Press, San Diego, CA, USA, pp. 315-322.

Wuczkowski, M., Druzhinina, I., Gherbawy, Y., Klug, B., Prillinger, H.J., Kubicek, C.P. 2003. Species pattern and genetic diversity of Trichoderma in a mid-European, primeval floodplain-forest. Microbiol. Res. 158: $125-133$ 